\title{
Sustainability and Socioeconomic Impacts of Bioenergy
}

\author{
Buse Şahin $^{1, *}\left(\mathbb{D}\right.$, Seda Aslan ${ }^{1}(\mathbb{D})$, Zeynep Doğa Ceylan ${ }^{1}\left(\mathbb{D}\right.$, Sevim Yolcular Karaoğlu $^{1}$
}

${ }^{1}$ Ege University, Faculty of Engineering, Chemical Engineering Department, 35040, Bornova, İzmir, Turkey

\section{Article History}

Received 13 June 2021

Accepted 10 September 2021

First Online 15 November 2021

\section{Corresponding Author}

E-mail: buseesahiin2@gmail.com

\section{Keywords}

Sustainability

Socio-economic impacts

Bioenergy

Renewable energy sources

\begin{abstract}
Biofuels are prominent energy sources among renewable energy sources in recent years. The reasons why biofuels are preferred can be listed as follows: biofuels can improve energy security, they can reduce greenhouse gas (GHG) emissions, they are renewable, they can increase farm income, they can create new jobs, they have physical and chemical properties similar to oil, and they are simple and familiar. The availability, and cost of the resources are important barriers for the effective development and spread of these technologies. There are increasing efforts to promote biomass production for industrial uses including biofuels and bio-products such as chemicals and bioplastic. Environmental sustainability is an important factor. Sustainability principles also apply at the economic and social levels. On sustainability, bioenergy creates both positive and negative effects on various environmental and socio-economic problems. These include social welfare, economic well-being, property rights, working conditions, poverty alleviation and more. Biofuel production can stimulate the agricultural sector and reduce poverty by increasing rural income. Fossil fuel dependence can be reduced, economic growth and jobs can be maintained, and the economic and environmental sustainability of production and processing industries can be improved by the use of bioenergy. In this study, sustainability and the socioeconomic impacts of bioenergy is examined by analyzing current social data and literature research. The most important findings of this study are the creation of different income channels and rural economic development by bioenergy transition around the globe.
\end{abstract}

\section{Introduction}

Beginning with the Industrial Revolution, energy demand has increased day by day due to the rapid population growth, developing manufacturing technologies and rivalry between countries. This demand was mainly met by the energy that comes from fossil fuels because of its high efficiency and easy accessibility. These types of fuels have been used steadily for many decades but in the past year's studies showed that fossil fuels have caused more damage than benefit in the long term. These damages raised in the environment, affecting the living creatures and their habitats. The biggest environmental challenge of our century, doubtless to say, is global warming and the main reason behind this challenge is the greenhouse gas emissions (GHG) caused by fossil fuels. In addition, these fuels are limited and under the risk of being depleted. These problems led people to use new solutions which are not hazardous to the environment and easily accessed for many years without the risk of coming to an end. The new solutions all led to sustainable energy sources, which are new types of energy that can protect their presence for many years in the nature without harming the living. Energies like solar, geothermal and wind are classified as sustainable energy and are trying 
to be adapted as a new solution, due to their characteristics. Renewable energy sources are being widely used for sustainable development and bioenergy is seem as one of the biggest alternatives for this development. The transition to sustainability in all aspects of modern life, has had different impacts considering not only the changes in the energy industry but also in the daily basis. The daily basis is mostly affected by socio-economic impacts which are built upon the social dynamics that rely on economic activities. In this case, usage of bioenergy sources has created highly vital socio-economic impacts like employment rates and land usage.

Related indicators of the socio-economic impacts of bioenergy were selected in this study. Then, the selected socio-economic impacts of bioenergy by previous studies of sustainability criteria for bioenergy was investigated.

The purpose of this study is to examine the socioeconomic impact of bioenergy and sustainability and the scope includes macroeconomic development and economic feasibility, rural economic development, land usage and food security, health and safety, employment rates and income and energy independence. The results were obtained by analyzing the economic data and examining rural development and energy security data.

\section{Macroeconomic Development and Economic Feasibility}

Because of their less damage to the environment, lower greenhouse gas emissions and other advantageous properties, bioenergy and other biobased materials are the alternatives to fossil fuels and other non-renewable energy sources (Lee, 2017). These properties have increased tendency of consuming or producing bioenergy in most of the countries. Increase in bioenergy consumption has an important and direct impact on economic growth of that country. For this reason, economic policies should be prepared considering the development of bioenergy infrastructure and increase of bioenergy supply, if consumption of bioenergy increases the income in countries. Policies that consider those issues can also help to achieve higher economic growth. Additionally, these policies should encourage the bioenergy consumption because of the development of exports and new employment opportunities (Bildirici, 2014). It can be seen that, bioenergy has an impact, that cannot be underestimated, for sustainable and economic development.

Energy independence is very important for the economy of a country; bioenergy and other renewable sources are playing an important role for the decrease of external dependence. From a macroeconomic point of view, bioenergy has also contribution on import substitution, which has an effect on gross domestic product (GDP); efficiency development; and assurance of diversification and energy supply. For countries that import energy, using of bioenergy is better because this can increase the local economy and employment. Additionally, increasing in bioenergy usage can lead to diversity in sources, consequently, long-term access for the energy supply with nearly constant prices can be provided (Domac et al., 2005).

Over the years, various new generation bioenergy has been established with technological development. These developments depend on funding from government or investors. These funding or investments depend on the economic feasibility studies. In addition to this, econometric theories and models are used to support assumptions and future behaviors of the economic participants (governments, investors, firms etc.). Econometric models can be helpful for bioenergy development because these models can explain factors such as biomass feed stocks and their transportation, international trade and also macro economy comprehensively (Lee, 2017).

\section{Rural Economic Development}

Bioenergy can not only provide sustainable and clean energy but also provide more revenue and improve the rural development. In some rural areas of developing countries, limited or lack of access of these types of energies affect economic productivity and also other essential basic services such as health care and education (Ackom et. al., 2011). Furthermore, bioenergy has the potential for new job opportunities and agricultural economy modernization. For these reasons, impact of bioenergy, especially in rural economic development, cannot be underestimated.

For the development of bioenergy, rural areas are more preferred. By applying of various thermal and biological processes (i.e. anaerobic digestion, combustion, gasification etc.), agricultural wastes can be transformed into biofuels, electricity and heat (Zafar, 2021). Improving the agricultural practices or agroforestry systems in rural areas for the aim of bioenergy can provide increase of biomass, cultivation cost reduction and better quality of environment. This way, major development of rural areas is also provided environmentally, economically, and socially.

It is important to consider some other issues to determine the role of the potential of using bioenergy in rural areas. One of them is cost of energy source; it is important to establish energy plantations in rural areas to make sure the supply of biomass at an affordable price for bioenergy applications. Additionally, the food versus energy issue for the land-using should be considered. Local fast-growing trees with suitable vegetable, fruit, and spice will not only ensure a secured biomass supply chain at economic and affordable prices but will also be sources of income for farmers and nutrition for the families in that region (Sharan \& Ramachandra, 2017). Other issue is the affordable and manageable equipment, and its conformity with the 
field. This can provide an encouragement for the farmers and other locals, so that prevalence of usage of bioenergy applications can increase. Also, the supply of the energy should be efficient, reliable and should not be limited only for the basic needs.

Bioenergy has a little difficulty for people who live in rural regions due to the lack of opportunities such as substructure and money. In these areas, lands are used for both energy sources and food cultivation, but this situation creates an increase in food prices. Because when the local lands start to become a source for bioenergy, the land used for food for the locals eventually starts not being able to meet the demands, rising the prices. If there is a local planning, organizing the land-usage and the farmers or workers, bioenergy has a major and also positive impact on rural areas in both economically and socially.

\section{Land Usage and Food Security}

Bioenergy is the form of energy that acquired from biomasses like foods, food crops, and non-food crops including the biodegradable fractions of industrial wastes. Due to consumption of these agricultural and forestry sources, bioenergy has raised two main ethical concerns on topics food security and land usage which are related to one another. Land usage management lays the foundation for food safety. In the countries that biofuel crops can grow, general agricultural capacity expand was observed. But the expansion has contradictory effects accordingly to land management since it can be considered as a scarce source.

In the Figure 1, expected land usage in 2030 compared with domestic production of biomass expected by PRIMES for the EUCO27 scenario which was made for the estimation of potential impact of European Unions' climate targets. It can easily understand that the Union expect an increasement in the domestic production cultivation. Growing crop-based bioenergy industry can lead to change in cultivation habits on these lands. At first sight, bioenergy has the potential for deforestation because of the low productivity in agriculture that causes growth for the potential of climate change. Locations in Latin America has great potential for the bioenergy crop. For instance, Brazil has 24.5 billion liters bioenergy production base on sugarcane ethanol (Miyake et al., 2012). Planted area and diversity in crops has been increased with increasing demand day by day in Brazil. To be able to keep up with this demand, land used for crop production moves to native forests and savannas. Destruction of these lands' results deforestation.

Another change in cultivation habit is the relegation of food crops by bioenergy crops. This kind of a usage has negative impact on food security that causes increasement in food demand which is also predicted to be affected negatively by climate change. Thus, the change in the cultivation leads directly to food security which is referred as fundamental human right. Examination of food security generally have been made on following topics: availability, accessibility, and stability. The studies show that bioenergy has a positive or at least neutral impact on these topics since it supports rural economy by supporting the local energy availability and accessibility (Souza et al., 2015). On the other hand, lack of sustainable policy on land usage will cause unproductive lands in rural areas which affect the population in rural negatively. Plantation of bioenergy crops instead of food crops may lead to food shortages and also high food prices, leaving the people hungry in relatively developing countries.

Although the bioenergy offers a good opportunity to the rural communities especially in improvement of utilization, economy, and food availability and so on, there are undeniable negative impacts like the rise in food prices and deforestation due to uncontrolled land usage. These consequences will eventually start a scarcity in these areas. In order to prevent the rise in food prices and also the deforestation, regulations must be established for planned transition to bioenergy.

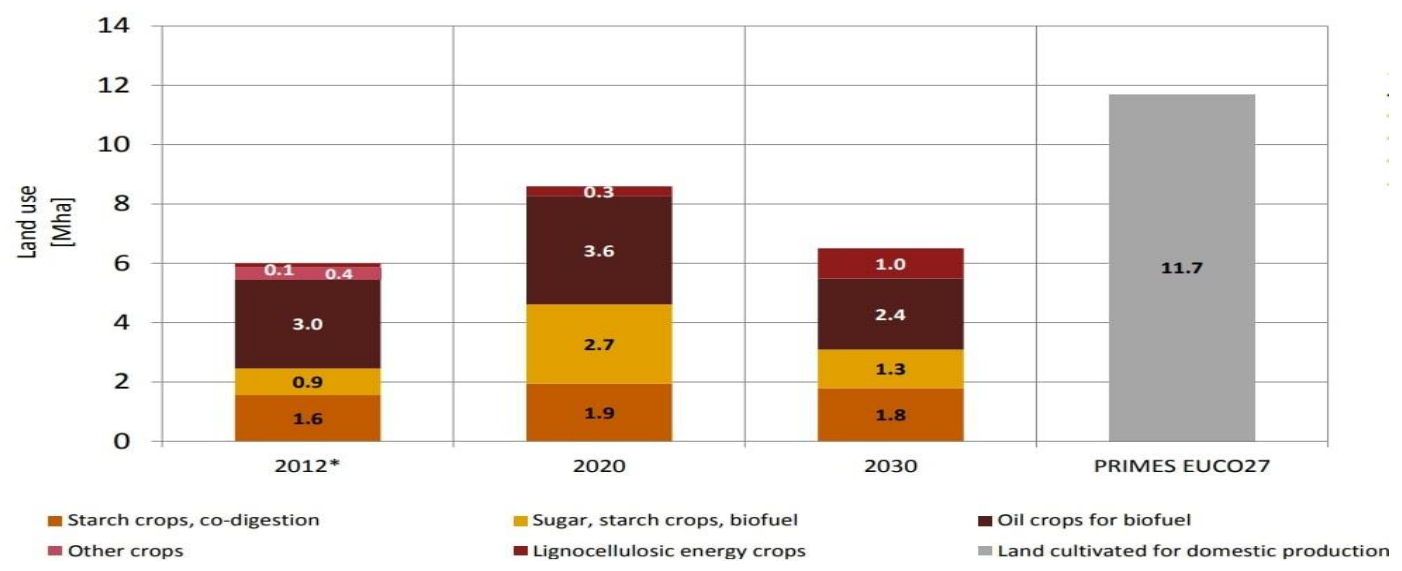

Figure 1. Developments in land used by years for domestic energy crop cultivation (Bogaert et. al., 2017). 


\section{Health and Safety}

Another issue on socioeconomic effect of bioenergy is health and safety of the nature. It is generally affected by economic reasons and can be categorized at a huge range from quality of air to nutrition. As mentioned before, rise of bioenergy production may cause better economy in the production areas (Souza et al., 2015). Especially in rural areas, expand in bioenergy production generates equal opportunities and also improves working conditions by improving economics of that areas. Additionally, bioenergy production increases nutrition awareness by providing food crop diversity. Expand in bioenergy production also provides clean energy source that linked directly to indoor pollution in homes which decreases the mortality when it decreases by reducing the unhealthy and low-quality cooking effects.

\section{Employment Rates and Income}

The developing technology has increased the dependence on the energy sector day by day. Considering it is one of the biggest sectors of employment in the world with nearly 58 million people employed in 2017 (Czako, 2020), even a slight change in the energy trends can cause major shifts in the employments. Basically, every part of life like shelter and food requires money, making the employment and income two major necessities to make a living for every adult in the world. Renewable Energy Jobs can be seen in Table 1.

The awareness of the highly dangerous pollutions all around the planet has shifted the energy production towards bioenergy affecting the employment rates and income. According to the Global Bioenergy Statistics 2020 prepared by World Bioenergy Association, after solar energy, bioenergy is the second biggest field of employment in the renewable energy sector.

Doubtless to say bioenergy has a big impact on employment and this impact shows increase year by year. Bioenergy offers income and employment in rural areas considering the agriculture-based economies in these locations. Because this type of energy can be obtained from energy crops which are plants that are grown specifically to be processed into energy fuels. Considering the agriculture patterns in these areas, energy crops can have significant effects and positive impacts on job and economic diversity in rural locations (Thornley, 2006).

According to The International Renewable Energy Agency's (IRENA) $6^{\text {th }}$ Renewable Energy and Jobs Report (2020), bioenergy employed approximately 3.18 million people in 2019. The bioenergy sector has multiple stages that starts off with the agriculture and ends with the last consumer. Beyond question to say, multiple stages bring multiple duties that require manpower. While the farmers and foresters are raising the crops, researchers from different branches like biology and chemistry are trying to find new solutions for bioenergy utilization.

The solutions lead to designs and manufacturing involving engineers, construction workers, technicians, and operators. The last step of the process ends with supplying the customer, employing many people along the distribution line. This multiple stage bioenergy process offers incomes throughout the world supporting the economy.

\section{Energy Security and Independence}

Energy security and independence are two highly important related keys for a country's development. Energy security has been explained by the United Nations as "the continuous availability of energy in varied forms, in sufficient quantities and at affordable prices." (Miller, 2016). Energy security is an important factor considering a society's development because without energy there will not be an economy and a country without an economy cannot show social development in many cases. Energy security is classified in two groups: long-term and short-term based on their availabilities. Long-term energy security mainly depends on the world's available energy sources that will meet the demand globally while short-term energy security

Table 1. Renewable energy jobs (all values in millions) (WBA, 2020)

\begin{tabular}{llllllll}
\hline & Total & Solar & Wind & Hydropower & Bioenergy & Others \\
\hline $\mathbf{2 0 1 2}$ & 7.28 & 2.25 & 0.75 & 1.66 & 2.40 & 0.22 \\
$\mathbf{2 0 1 3}$ & 8.55 & 2.77 & 0.83 & 2.21 & 2.50 & 0.23 \\
$\mathbf{2 0 1 4}$ & 9.50 & 3.25 & 1.03 & 2.04 & 2.99 & 0.19 \\
$\mathbf{2 0 1 5}$ & 10.0 & 3.71 & 1.08 & 2.16 & 2.88 & 0.20 \\
$\mathbf{2 0 1 6}$ & 10.1 & 3.92 & 1.16 & 2.06 & 2.74 & 0.24 \\
$\mathbf{2 0 1 7}$ & 10.5 & 4.18 & 1.15 & 1.99 & 3.05 & 0.16 \\
$\mathbf{2 0 1 8}$ & 11 & 4.48 & 1.16 & 2.05 & 3.18 & 0.18 \\
$\mathbf{2 0 1 9}$ & 11.5 & 4.57 & 1.17 & 1.96 & 3.58 & 0.18
\end{tabular}


concerns more about the continuous supply for the consumers, independent of time (Miller, 2016). Doubtless to say, each country is responsible for their own economic growth and must have a significant plan for energy security. Energy security has faced many threats in history and can still be considered in risk. These threats can be caused by certain factors like natural catastrophes or political disagreements with or in rich oil producing countries (Srivastava, 2016). In our day, energy security is not only about the energy source itself, but also about the distribution network.

Considering the countries having to rely on different countries for energy due to the fact that not every energy source is present geographically in every location can cause major energy challenges in the future. Countries leading towards renewable energies like bioenergy that can be sourced domestically, are more advantageous and will certainly see the benefits more in future because they will eventually start relying less on fossil fuels. This decrease will also have a positive impact economically, considering the elimination of expensive foreign fuel import. Energy independence is very critical in this century and the transition towards bioenergy can support a country socially and economically energy-wise.

\section{Results}

Bioenergy can be considered as one of the most prominent energy sources globally to prevent hazardous effects that fossil fuels leave behind. On sustainability, bioenergy creates both positive and negative effects on various environmental and socio-economic problems. While considering the impact of bioenergy on socioeconomic basis, both sides must be evaluated in order to obtain the suitable option. It was observed that using bioenergy can increase employment rates while creating income channels and support macroeconomic development. It can also provide energy security and independence. Bioenergy has multiple impacts socioeconomically, including:

- Social welfare,

- Economic well-being,

- Property rights,

- Working conditions,

- Poverty alleviation

The socioeconomic impact of bioenergy and sustainability investigated by this study and the scope includes macroeconomic development and economic feasibility, rural economic development, land usage and food security, health and safety, employment rates and income and energy independence. Economic policies should be prepared to encourage the bioenergy consumption because of the development of exports and new employment opportunities. Thus bioenergy has an impact, that cannot be underestimated, for sustainable and economic development. Local economy and employment can be increased by use of bioenergy and its import. Increase in bioenergy usage can lead to diversity in sources. Then long-term access for the energy supply with nearly constant prices can be provided. Bioenergy provide more revenue and improve the rural development by providing sustainable and clean energy. New job opportunities and agricultural economy modernization can be achieved by bioenergy. Impact of bioenergy, especially in rural economic development, cannot be underestimated. By the consumption of agricultural and forestry sources, bioenergy has increased two main ethical concerns on topics food security and land usage which are related to each other. Land usage management lays the foundation for food safety. In the countries which biofuel crops can grow, general agricultural capacity expansion was observed. But this expansion has conflicting effects with land management since it can be considered as a scarce source. Bioenergy provides positive impacts to the rural communities especially in development of economy, food availability, and utilization etc. But there are inevitable negative impacts like deforestation due to uncontrolled land usage and the rise in food prices. Another topic on socioeconomic effect of bioenergy is health and safety of the nature. It is generally affected by economic reasons and can be categorized at a huge range from quality of air to nutrition. Bioenergy production provides food crop diversity and increases nutrition awareness. Increase in bioenergy production also provides clean energy source which is linked directly to indoor pollution in homes. This decreases the mortality by reducing the unhealthy and low-quality cooking effects. The employment and income are two major necessities to make a living for every adult in the world. The search for solutions to environmental pollution has shifted energy production to bioenergy, which affects employment rates and income. Bioenergy is the second biggest field of employment in the renewable energy sector after solar energy. Bioenergy has a big impact on employment and this impact increases year by year. Countries which use renewable energies like bioenergy are more advantageous and will exactly see the advantages more in future. Because they will finally start depend less on fossil fuels. This decrease will also have a positive impact economically by considering the elimination of expensive foreign fuel import. The transition to bioenergy can support a country socially and economically in terms of energy.

Bioenergy helps the rural areas the most by providing jobs, food diversity and land utilization. Doubtless to say, this supports the economic well-being of the rural populations providing social welfare and decreasing the local poverty, eventually. The decrease in the GHG emissions caused by the decarbonization of the industry and transition to bioenergy also creates a healthier environment not only for the population but also for the industry workers by giving cleaner working conditions. While bioenergy has many positive impacts on people and the environment, it also has major negative impacts such as causing deforestation and food 
scarcity due to improper land usage. Transition towards bioenergy will open many doors but the side effects of this transition cannot be underestimated and the impact it will have, positive or negative, will depend on how it will be managed in the future.

\section{Conflict of Interest}

The authors declare that they have no known competing financial interests or personal relationships that could have appeared to influence the work reported in this paper.

\section{References}

Ackom, E., Pedersen, M.B., \& Christensen, J.M. (2011). Bioenergy: The potential for rural development and poverty alleviation: Summary for policy-makers. Global Network on Energy for Sustainable Development (GNESD). GNESD-SPM-BET-11/2011. ISBN 978-87-5503916-2

Bildirici, M.E. (2014). Relationship between biomass energy and economic growth in transition countries: panel ARDL approach. GCB Bioenergy, 6(6), 717-726. https://doi.org/10.1111/gcbb.12092

Bogaert, S., Pelkmans, L., Van den Heuvel, E., Devriendt, N., De Regel, S., Hoefnagels, R., ... \& Hernández, A. (2017). Sustainable and optimal use of biomass for energy in the EU beyond 2020. European Commission: Amsterdam, The Netherlands, 1-198.

https://www.ec.europa.eu/energy/sites/ener/files/doc uments/biosustain_report_final.pdf

Czako, V. (2020). Employment in the energy sector status report 2020 (EUR 30186 EN), Publications Office of the European Union, Luxembourg. ISBN 978-92-76-18206 https://doi.org/10.2760/95180, JRC120302.

Domac, J., Richards, K., Risovic, S. (2005). Socio-economic drivers in implementing bioenergy projects. Biomass and Bioenergy, 28(2), 95-106. https://doi.org/10.1016/j.biombioe.2004.08.002

IRENA (2020), Renewable Energy and Jobs - Annual Review 2020, International Renewable Energy Agency, Abu Dhabi. ISBN: 978-92-9260-266-6

Lee, D. (2017). Econometric assessment of bioenergy development. International Journal of Hydrogen Energy, 42(45), 27701-27717. doi.org/10.1016/j.ijhydene.2017.08.055

Miller, B.G. (2016). The Future Role of Coal. Clean Coal Engineering Technology (2 ${ }^{\text {nd }}$ ed.) (pp. 757-774). Butterworth-Heinemann. https://doi.org/10.1016/C2009-0-20236-4

Miyake, S., Renouf, S., Peterson, A., McAlpine, C., Smith, C. (2012). Land-use and environmental pressures resulting from current and future bioenergy crop expansion: A review. Journal of Rural Studies, 28(4), 650-658. https://doi.org/10.1016/j.jrurstud.2012.09.002

Sharan, H.N., \& Ramachandra, K. (2017). Bioenergy for rural development. Encyclopedia of Sustainable Technologies, 277-287. https://doi.org/10.1016/B978-0-12-409548-9.10152-6

Souza, G.M., Victoria, R.L., Joly, C.A., \& Verdade, L.M. (2015). Bioenergy and food security. Bioenergy \& Sustainability: Bridging the Gaps (pp. 90-137). ISBN: 978-2-9545557-06

Srivastava, B. (2016). Energy security: Today and tomorrow. Humanities \& Social Sciences Reviews, 4(2), 59-67. http://dx.doi.org/10.18510/hssr.2016.421

Thornley, P. (2006). Increasing biomass-based power generation in the UK. Energy Policy, 34(15), 2087-2099. https://doi.org/10.1016/j.enpol.2005.02.006

World Bioenergy Association. (2020). Global bioenergy statistics 2020. Retrieved from http://www.worldbioenergy.org/uploads/201210\%20 WBA\%20GBS\%202020.pdf.

Zafar, S. (2021). Role of biomass energy in rural development. BioEnergy Consult. Retrieved May 2021, from https://www.bioenergyconsult.com/biomass-energyrural-development/. 